\title{
South African patient's acceptance of generic drugs
}

\author{
Varsha Bangalee
}

University of KwaZulu Natal, Discipline of Pharmaceutical Sciences

\section{DOI: http://dx.doi.org/10.4314/ahs.v15i1.37}

\section{Introduction}

Access to therapeutic drugs form an integral part of any successful healthcare system. The high cost of drugs, however, remains a barrier to accessibility and improved health to the majority of the South African population ${ }^{1}$. The promotion of generic drug consumption could potentially be an important cost-saving mechanism in this regard for final consumers, insurance providers, and government. In 2001, the South African government subsequently passed the law which allows generic substitution of branded medicines with generics, provided that the patient approves of the substitution. In the discussion over the use of generic drugs, patient perceptions have often been neglected. Currently very little knowledge exists on the perception and attitudes of South African citizens with regard to the use of generic drugs. An appraisal of the available literature suggests that although patients do not completely have a negative opinion of generic drugs and acceptance is growing, there still exists room for improving perceptions.

Similar to several international studies, the South African patient's acceptance of generics is influenced by age, educational level, perceived seriousness of illness, generic drug information, and doctor and pharmacist perceptions. In general, participants with lower incomes and participants with lower levels of education held poorer attitudes toward generic drugs ${ }^{2}$. Individuals with tertiary education were found to have a more positive attitude toward generics than individuals with no tertiary education ${ }^{3}$.

\section{Corresponding author: \\ Varsha Bangalee \\ Discipline of Pharmaceutical Sciences, \\ School of Health Sciences, \\ University of KwaZulu Natal \\ Private Bag X54001 \\ Durban 4000, South Africa \\ Email: bangalee@ukzn.ac.za}

Patients often confuse "generic brands" of therapeutic drugs with counterfeit products especially due to the cost difference 0associated with these products. Free generic medication issued by the public health facilities are viewed as inferior, treated with suspicion and regarded as being of poor quality ${ }^{4}$. There are however citizens who view drug quality as product attributes and expected consequences of taking a particular medicine. Irrespective of whether the drug was a generic, original, supplied for free or purchased from a pharmacy, the drug was considered good quality provided that it treated the symptoms.

Studies also consistently show that, participants frequently have very little understanding of generic medicines. Most patients are not adequately informed about the difference or similarities between original and generic drugs by healthcare providers. Additionally patients feel that they have limited influence in the choice of generic substitution. Patients with increased level of education, and those who received proper counselling, were found to be more accepting of generic substitution and tended to view generic drugs as a valuable reform. Patients would be more inclined to choose a generic drug if the decision was supported by their doctor rather than the recommendation of the pharmacist.

The use of generic drugs to treat chronic diseases is also received with mixed acceptance. Certain groups of patients viewed the cost saving benefit very positively. South African patients also related quality to the ability of the medication to do what it was prescribed to do. Therefore drugs that treated their symptoms - whether generic or original - were fully accepted provided they fulfilled their role. On the other hand, there were also patients who were not accepting of generics to treat chronic conditions, as they viewed them as inferior, and likely to have greater side effects than original drugs. Some of the concerns amongst chronic drug users were with regard to reduced effect of the drug or new or increased side effects. In addition, chronically ill patients who take several drugs for longer 
periods of time admitted to feeling unsettled - particularly when being offered different generics each time they purchase their medication. The effect of brand to generic and generic to generic switches leads to intentional non-adherence in erroneous use. This is especially problematic with medication classes that have narrow therapeutic margin like anti-epileptics.

\section{Recommendation}

It is strongly evident that more research is required with respect to patient perceptions in relation to generic drug usage from the South African perspective where cost saving is desired more than developed countries.

Existing negative perceptions surrounding the quality of generic medicines need to be addressed to ensure that patients use them with confidence. A novel approach to addressing negative perceptions would be to institute national educational campaigns to increase the uptake of generic medicines by consumers. Government policies are destined to fail in execution if inadequate attention is paid to consumer perceptions as this affects behaviour and consumption patterns.

Policy makers need to emphasize to patients what is being done to ensure that generic drugs available in the South African market are safe and of an acceptable quality. More stringent policy's should be exerted on pharmaceutical companies to ensure that they do not produce poor quality medication and they should further be held accountable for any inferior products reaching the market.

Patient acceptance of generics improved when they were viewed in a positive light by the healthcare professionals treating them. For generic substitution policy to succeed healthcare providers therefore also need to adopt a positive attitude toward generics medicine. These groups require credible information with regard to the products they recommend and dispense. Since a manufacturer's reputation influences the confidence of professionals, generic manufacturer should provide more robust evidence demonstrating therapeutic equivalence of their products. Efforts should be made by generic companies to improve practitioner and pharmacist knowledge of their products. The perceived risks and inequality toward generic medicines will decline if patients have acknowledged the benefits of generic medicines obtained through repeated exposure to these products.

Education of healthcare workers is imperative and they should be made aware of their role and responsibility in improving patient perceptions and reducing healthcare costs. Implementation of present intervention needs to target all health care professionals to ensure a consistent message is communicated to the wider South African public. Polices need to be embraced from a grass route level i.e. Universities training healthcare professionals and professional bodies and councils.

Finally pharmacovigilance programs can also have a significant impact on increasing confidence in the therapeutic equivalence of generics. Healthcare professionals and patients alike should be encouraged to report any problems with medication. Furthermore appropriate action in response to all reports should be implemented. Action must be taken to ensure than in the government's effort to reducing costs of drugs, this should not translate into inferior therapy and poor health outcomes.

\section{References}

1. Gray A, Matsebula T. Drug pricing. In: South African Health Review. Durban: Health Systems Trust, 2000. http://www.hst.org.za/sahr/2000/chapter9.htm (accessed 12 February 2014).

2. Patel A, Gauld R, Norris P, Rades T. "This Body Does Not Want Free Medicines": South African Consumer Perceptions of Drug Quality. Health Policy Plann 2010; 25:61-69.

3. Igbinovia ME. The perceived benefits of generic versus branded medicines, MBA dissertation. Pretoria: University of Pretoria, 2007. http://upetd.up.ac.za/ thesis/available/etd-03232010-132831 (accessed 15 February 2014)

4. Patel A, Gauld R, Norris P, Rades T. Quality of Generic Medicines in South Africa: Perceptions Versus Reality-a Qualitative Study. BMC Health Serv. Res 2012;12:297. 